\title{
COMPLEX TREATMENT OF EPITHELIAL TUMORS OF THE THYMUS WITH A COMBINATION OF ENDOVASCULAR TECHNOLOGIES
}

\author{
Roman Kravchenko ${ }^{1}$ \\ Yuriy Avdosyev ${ }^{2}$ \\ Oleg Luzan ${ }^{3}$ \\ Yakov Ivashchik ${ }^{4}$
}

DOI: https://doi.org/10.30525/978-9934-26-050-6-16

Epithelial tumors of the thymus occur in the thymus and include thymomas and carcinomas of the thymus. Thymomas are the most common primary tumor in the anterior mediastinum, but are generally rare (1.5 cases / $1,000,000)$. Although thymomas can spread locally, they are much less invasive than thymic carcinomas. Patients with thymic carcinomas often have metastases. The 5-year survival of patients with thymoma reaches $90 \%$. At the same time, the 5-year survival rate for thymic carcinoma is approximately $55 \%$ (NCCN Guidelines. Version 1.2020).

Surgical treatment as an independent method can be used only when there are thymus tumors in encapsulated and minimally invasive tumors in the first degree, rarely in the second degree. In all other cases, patients are subject to combined, complex or conservative treatment. In combined and complex treatment, preference should be given to neoadjuvant methods, which allows to achieve regression of the tumor, reduces its volume, limits the invasion of surrounding tissues, as well as to transform the inoperable process into operability.

Endovascular technologies, namely regional chemotherapy, in the preoperative period, as a preparatory stage, will increase the level of ablastics and antiblastics in surgical treatment of thymus and reduce the percentage of cytostatics on the whole body, as in intravenous administration. At patients with a paraneoplastic syndrome it is necessary to increase term of regression of displays of these syndromes.

Intra-arterial administration of chemotherapeutics has certain advantages:

- cytostatics in the arteries that supply blood to the tumor are injected directly into the affected area, which allows you to significantly increase the concentration of the drug in the tumor itself;

\footnotetext{
${ }^{1}$ Chernihiv Regional Hospital, Ukraine

Kharkiv Medical Academy of Postgraduate Education, Ukraine

${ }^{2}$ Kharkiv Medical Academy of Postgraduate Education, Ukraine

${ }^{3}$ Chernihiv Regional Hospital, Ukraine

${ }^{4}$ Chernihiv Regional Hospital, Ukraine
} 
- reduces the toxic effects of chemotherapy on the whole body;

- longer action of drugs allows long-term contact of the cytostatic with tumor cells at all stages of the cell cycle.

Another main detail of treatment is that after the introduction of the cytostatic, it is necessary to introduce special emboli (microspheres) to block the removal of the chemotherapeutic agent.

The analysis of treatment is taking into account the stage, anamnestic data, the development of clinical manifestations, the results of laboratory and instrumental methods of examination.

According to this analysis, intra-arterial chemoembolization was selected from the complex treatment of thymic epithelial tumors, which, as described above, allows to act directly on tumor cells.

According to our evidence, taking into account clinical and anamnestic (complaints), laboratory, instrumental (CT OGK with IV contrast), certain conclusions were made in the treatment of thymic tumors.

According to our observations, a method of complex treatment of thymic tumors was developed. In this technique, we used regional chemotherapy (namely intra-arterial administration of chemotherapy - cytostatics) as the main method.

Evidence on surgical treatment of benign thymus tumors for 2018-2020 $(\mathrm{n}=9)$ :

- With myasthenia - 5 patients;

- Without symptoms of illness -4 patients.

Thoracotomy (thymomectomy, thymectomy) -5 patients.

$\mathrm{X}$-ray endovascular operation -3 patients.

Conservative therapy -1 patient.

In a month after treatment, 7 patients had no symptoms of illness.

One patient had complications in the form of recurrence of myasthenia gravis and cerebral edema, which required tracheotomy and resuscitation.

Evidence on surgical treatment of malignant tumors of the thymus for 2018-2020 ( $\mathrm{n}=5)$ :

With superior vena cava syndrome -4 patients.

Thoracotomy - 1 patient.

Operation + intra-arterial administration of chemotherapy -1 patient.

Radiation therapy + intra-arterial administration of chemotherapy -1 patient.

Conservative therapy -2 patients.

Died in the early postoperative period -1 patient.

Died of concomitant complications (brain edema, acute cardiovascular failure) without surgery -1 patient.

In general, died 2 (40.0\%) patients.

Object of study. Epithelial tumors of the thymus gland. 
Subject of study. Indicators of survival and quality of life of patients with malignant thymoma without surgical treatment. The results of radical surgical treatment after regional chemotherapy. Indicators of ablastic and antiblastic. Indicators of results of patients with paraneoplastic syndrome.

The aim of the study. Increase the effectiveness of treatment of patients with epithelial tumors of the thymus by using intra-arterial chemoembolization as a neoadjuvant therapy to create ischemia and high concentrations of cytostatics in tumors for a long period of time to achieve devitalization of tumor tissue and reduce overall toxicity of chemotherapy.

\section{Objectives of the study.}

1. To determine the causes of unsatisfactory results of treatment of patients with epithelial tumors of the thymus using standard methods.

2. Improve the technique of intra-arterial chemoembolization in epithelial tumors of the thymus gland (technology, choice of cytostatics).

3. To study the dynamics of biochemical markers (AFP, HGT) and antibodies to acetylcholine in paraneoplastic syndrome using intra-arterial chemoembolization.

4. To study pathomorphological changes in tumor tissue using intraarterial chemoembolization.

5. To compare the clinical efficacy (increased tumor operability) of intraarterial chemoembolization in the complex therapy of patients with epithelial tumors of the thymus gland.

\section{References:}

1. NCCN Guidelines. Version 1.2020. Thymomas and Thymic Carcinomas.

2. Ganul A.V. Optimization of diagnosis and treatment of patients with malignant tumors of the mediastinum. Oncology. - 2009, v. 11, № 2. - P. 131-135.

3. Borisyuk B.O. Intraarterial regional polychemotherapy in the complex treatment of malignant neoplasms of the mediastinum. Oncology. - 2009, v. 11, № 2. - P. 136-138.

4. Guide to angiography / ed. I.H. Rabkin. - M.: Medicine, 1977. - P. 280.

5. Vetshev P.S. Thymus / P.S. Vetshev, O.V. Zaratyants, V.A. Zhivotov // In the book. : A.P. Kalinin, H.A. Maistrenko, P.S. Vetshev. Surgical endocrinology: a guide. - SPb.: Peter, 2004. - P. 347-462.

6. Vetshev P.S. Surgical treatment of thymus in patients with generalized myasthenia gravis / P.S. Vetshev, L.I. Ippolitov, D.M. Merkulova, etc. // Surgery. 2003. - № 10. - P. 15-20.

7. Interventional radiology in oncology (ways of development and technology): scientific and practical edition / ch. ed.: A.M. Granov, M.I. Davydov; ed.: P.G. Tarazov, D.A. Granov, B.I. Dolgushin, V.N. Polysalov, A.A. Polikarpov. SPb.: LLC «Publishing house FOLIANT», 2007. - P. 344.

8. Nikitenko A.I. Thoracoscopic thymectomy for myasthenia gravis / A.I. Nikitenko, E.G. Nikitenko, A.M. Zhelannoe, etc. // Endoscopic surgery. - 2006. № 2. - P. 94-95. 
9. Seagal E.I. Videothoracoscopy in the diagnosis and treatment of benign and malignant diseases of the chest: 10 years of experience / E.I. Seagal, R.G. Burmistrov, R.G. Hamidullin // Endoscopic surgery. - 2005. - № 1. - P. 138-141.

10. Kharchenko V.P. Diseases of the thymus gland / V.P. Kharchenko, D.S. Sarkisov, P.S. Vetshev and others. - M.: Triad X, 1998. - 232 p.

11. Guide to chemotherapy of tumors. 4th edition Perevodchikova N.I., Gorbunova V.A. (ed.) Ed. «Practical Medicine», 2015. - 688 p.

12. Detterbeck F.C. Thymic tumors / F.C. Detterbeck, A.M. Parson // Ann. Thorac. Surg. - 2004. - Vol. 77. - P. 1860-1869.

13. Dinkel H.P. Endovascular treatment of malignant superior vena cava syndrome: is bilateral Wallstent placement superior to unilateral placement? / H.P. Dinkel, B. Mettke, F. Schmid et al. // J. Endovasc. Ther. - 2003. - Vol. 10. - P. 788-797.

14. Jaretzki A. Thymectomy for myasthenia gravis : analysis of controversies patient management / A. Jaretzki // Neurologist. - 2003. - Vol. 9. - P. 77-92.

15. Lanciego C. Stenting as first option for endovascular treatment of malignant superior vena cava syndrome / C. Lanciego, J. L. Chacon, A. Julian et al. // Am. J. Med. - 1998. - Vol. 104. - P. 78-84.

16. Lisak R.P. (ed.) Handbook of myasthenia gravis and myasthenic syndromes / R.P. Lisak (ed.). - New York-Basel-Hong Kong : Marcel Dekker, inc., 1994. - 422 p.

17. Mack M.J. Video-assisted thoracoscopy thymectomy for myasthenia gravis II / M.J. Mack // Chest Surg. Clin. N. Am. 2001. - Vol. 11, № 2. - P. 389-406.

18. Masaoka A. Extended transsternal thymectomy for myasthenia gravis / A. Masaoka // Chest Surg. Clin. N. Am. - 2001. - № 2. - P. 369-387. 